\title{
Editorial: On Phonosophy
}

In proposing this hypothetical binary of phonosophy, by combining sound (phonos) and wisdom (sophia), we aim to explore the potential of the term - and its aligned sophic. Skolimowski (1981) in his short original treatise called Eco-philosophy said that 'Logos is a very subtle and all-pervading form of praxis' (viii), which is how we imagine a life of phonosophy must be lived. In light of the effectiveness of wisdom being applied in the realm of Logos (philosophy), what would the effect of wisdom be when coupled with Phonos? Goethe indicated that 'poetry points to the riddles of nature and tries to solve them by means of the image. Philosophy directs itself to the riddles of reason and attempts to solve them by means of the word. Mysticism considers riddles of both nature and reason and seeks to solve them through both word and image' (as cited in Allen 1978). What 'riddles' do phonosophers attempt to solve? In the following articles, we explore the dynamics of a mutually informed organisation of sonic nature and sense via a practice of resonant sentience.

The papers responding to this call come from different walks and countries: from China, Chile, North America, Australasia and the EU. At the time of our first call-for-papers On Phonosophy, people were in the habit of gathering physically to listen to music in groups taking the form of what were once called 'concerts' and 'dance parties'. However, at the time of the release of this issue, due to a pandemic, musicians and audiences only connect with each other from their homes over the internet. The world has gone through some significant changes over the time period of writing and reviewing these papers and we need to reflect more than ever now on how electronic and networked music go forth to get this world resonating again. We hope this issue can be a new sensible start down the long and wising sonic road ahead.

The first paper, 'On Phonosophy' by Ken Fields, most directly addresses the theme and serves as a good first-shot introduction to phonosophy. What is discovered is that modernism is not, strictly speaking, a recent dynamic, but a long process of the becoming of Logos - albeit one that crosses a critical threshold and accelerates after the time of the Renaissance. However, the Logos does not exist in a pure deterministic state, free from the affect of a resonant sensorium, nor disconnected from an energetic temporal flux.
Where we currently find ourselves in that Heraclitian stream seems rather crucial at this point in history, and thus requires some serious reflection on our field's approach to sonic automation, machinic mimicry and sonic communication. Jean Luc Nancy and Henri Bergson take centre stage in this article.

Next, Hubert Gendron-Blais resonates on the music thinking process in the unfolding of his piece Résonances manifestes. Considered here is the profound epistemological shift from the perspective of power and the social to the deeper processes of lived experience. There is also the recognition of mutuality in the manifestation of sense and concept in the process of sonic thinking. This article looks at the inherent processes involved in the ecology of the sonic event itself, a process that is outlined with reference to Whitehead, Deleuze and Guattari, and Manning. Gendron-Blais's article signals a clear convergence and turning point in the field of electroacoustic music towards a conception of phonosophical inquiry.

Adel-Jing Wang provides a view that has been sought over the last several decades in terms of a coherent epistemological bridge between East and West cultural practices in the field of artistic/ technological creation. What coheres is how Shanshuithought in experimental music practices in China and new phonosophical perspectives come together in this issue in such a seamless manner. From her abstract: 'Shanshui-thought cultivates an existential gesture of following rather than obeying or conquering; it requires tacit resonance rather than object knowing.' Wang introduces essential concepts from the Chinese scholarly and artistic tradition of Shanshui-thought, such as dan, you, yinyun and huwei tuotai that followers of Cage and Varese will directly relate to. In the light (or sounds) of contemporary Chinese and Western soundscape practices through the investigation of the ancient tradition of Chinese landscape painting, one will easily recognize emerging and complementary cultural seeds that most assuredly will flourish in the new space of the term phonosophy.

Susan Frykberg dares address the elephant not in the room of academia: spirituality. She references a number of renowned composers in the context of electroacoustic music who do draw on spiritual or religious material in their work, but notes the very problematic aura that surround the words and this 
discussion. Her solution is to bring in Robert Emmons theory of spiritual intelligence (SI). She organises the discussion around three categories: traditional approaches - which refers to those works which reference sacred texts; experimental - which refers to the idea that experimentation with sound is inherently a sacred exploration; and ancient ways of knowing works that reference ancient scriptures or traditions.

Jiayue $\mathrm{Wu}$ approaches her work 'From Physical to Spiritual: Defining the Practice of Embodied Sonic Meditation' in the tradition of Tibetan Buddhism. In the context of electroacoustic, academic musical practice, she frames her approach as a hybrid inquiry between her own meditational practice, digital music interface design, and human-centred design principles. This is backed by theories in neurological research, Csikszentmihalyi's Flow theory and embodied mind concepts in the tradition of Fransisco Varela, George Lakoff and Marc Leman. She provides a short critique of Tibetan cultural influences in pieces by Zhang Xiaofu and Pierre Henri that helps the uninitiated reader to distinguish between the different approaches in making use of (appropriating) religious cultural material - such as that referred to in Frykberg's article.

In his short article 'Swamp, Sound and Sign', along with the composition it frames, William Bertrand phonosophises on interspecies difference in compositional practices. The idea of sonic thinking and knowing flows from the previous articles and enters the dense conceptual bogs in a chorus of sonic signs and icons that, as Bertrand states, can serve as a non-dualistic bridge between human and animal differences. As he argues, 'spanning this difference is in some respects a characteristically sonic or artistic act, and that this knowing, decentred subject-object is a sonic or imagistic knowing and leaping - be it an act of listening, composition, or thought.'

Sam McAuliffe interviews Cat Hope, finding a particular wisdom in her approach to digital scoring which 'attempts to address issues of hierarchy and segregation that arise with respect to the somewhat alienating character of Western notation'. Hope is known for her screen-based scrolling scores that may contain embedded sound files which can then be controlled and shared over networks. Continuing the graphic music tradition of Xenakis and Ligeti, she brings in the full range of affordances that new interactive graphic technologies bring to the tablet. As alphabets, writing and the printing press have shown, innovation in representation is not a trivial issue of translation. The hope of Hope is that a great movement of expression will result in the graphic vernacularisation of Classical Western Art notation.

Chilean composer Alejandro Albornoz applies the aesthetic theories of his predecessor, Chilean poet Vicente Huidobro, to electroacoustic music composition. Huidobro's work paralleled art movements of the early twentieth century, including dadaism, surrealism and futurism, conceiving of his artistic system as a way to create machinic or autonomous artistic organisms. Following Huidobro's theory of 'creacionismo', Albornoz's artistic strategy strives to balance intuition and rationality in placing 'poetry and voice as a driving force in the compositional process, using semantic and phonemic juxtaposition which aim at the creation of altered states or superconsciousness'.

Thembi Soddell seeks in the gap of the acousmatic experience (to refer or not to refer) to exploit and explore that ambivalence in order to understand states of psychological anxiety and distress. The gap acts like a sonic metaphor, likening the drawing or severing of connections between abstract concepts and concrete experience to the same operation with abstract and concrete sounds; in effect, likening reduced listening to reduced (dissociated) living, which is a way to understand mental illness itself. In his article 'The Acousmatic Gap as a Flexile Path to Self-Understanding: A case for experiential listening', Soddell extends the theories and therapies based around experientialism to the listening experience.

Vadim Keylin treats the politics of sound art from the stance of postcritical listening. His radical empiricist, autoethnograhic accounts of several works of sound art shows how critical analysis as 'detached from the lived experience leaves behind a wealth of meanings'. His framework pivots around the concept of affordance, specifically as applied in three ways: how the participant makes sense, how participants can use the work outside of aesthetic experience and how access to participation is carried out. These as a whole point towards a relationality between the 'materiality of the artwork and the individual listener's sensorium [that] opens up the field of political possibilities'.

Mo Zareei simply presents the noise object itself as an elegant dance of the minimalistic beauty of electromechanical devices and their sounds. This provides the opportunity to discuss audiovisual materialism in a completely literal sense in counterbalance to the currently parallel discussions of signal-centric realism/materialism. The author strives for a balanced aesthetic of sculptural and sonic properties, with emphasis on their co-present affect. Zareei's piece, 
Material Music, demonstrates his approach to soundbased art.

On Phonosophy begins to build a literature and methodology around the term. Let's be motivated by the possibility that our own discipline has played a part in ecological destruction, diminished humanity and displaced species (sonic colonialism).

Ken Fields (kenfields@ucsb.edu)

Marc Battier (marc.battier@paris4.sorbonne.fr)
Paul Rudy

(rudyp@umkc.edu)

Tyler Kinnear

(tkinnearsound@gmail.com)

\section{REFERENCES}

Allen, P. M. 1978. Introduction. In Vladimir Soloviev, Russian Mystic. Great Barrington, MA: Steinerbooks.

Skolimowski, H. 1981. Eco-Philosophy: Designing New Tactics for Living. Boston: Marion Boyars. 